\title{
A Clinical Perspective on Triple Negative Invasive Breast Carcinomas with Comedo Necrotic Features
}

\author{
Taneisha McFarlane ${ }^{1 *}$ and Sami Shousha ${ }^{2}$
}

*Correspondence: t.mcfarlane@imperial.ac.uk

\author{
CrossMark
}

$\leftarrow$ Click for updates

\begin{abstract}
'Department of Material Engineering, Royal School of Mines, Imperial College London.
${ }^{2}$ Histopathology Department, Charing Cross Hospital, Imperial College Healthcare NHS Trust, London, United Kingdom.
\end{abstract}

\begin{abstract}
Triple-negative breast carcinomas are characterized by its unique molecular profile, histological and clinical features and distinct patterns of metastasis, and lack of targeted therapies. Most, but not all, triple negative tumours (TNTs) have aggressive clinical behaviour and poor prognosis, yet they are grouped together, when studying their behaviour and management because of their triple negativity. Some members of this group, particularly adenoid cystic and secretory carcinomas, have a distinct microscopic appearance which is well recognised by pathologist and can be easily separated from the rest and managed differently. However, there are other morphological subgroups of triple negative breast carcinomas which are not well recognized and or characterised. One of these includes TNTs with extensive 'comedo' necrosis.

This study aimed at comparing the demographic features and prognosis of triple negative tumours with comedo necrosis with the rest of triple negative carcinomas. In this study we found no statistically significant difference regarding age, tumours size or the expression of CK 5, CD10, Maspin or Claudin3 and 4. Claudin 1 was significantly less expressed in tumours with comedo necrosis (13\% vs $26 \%$ ) for tumours with no comedo necrosis and a significant difference in lymph node status and metastases follow up was observed.

This can suggest that tumours with comedo necrosis does attribute different behavioural pattern from those without, they are less aggressive and have a good outcome and can be a good prognostic indicator, knowledge of these tumours can be valuable in patient management.
\end{abstract}

Keywords: Breast, Comedo Necrosis, Triple Negative Breast Cancer, Maspin, Claudin 1, Claudin3, Claudin4

\section{Introduction}

Triple negative breast cancer (TNBC) is a group of cancer that is identified by the absence of expression of oestrogen receptor (ER), progesterone receptor (PgR) and the absence of human epidermal growth factor receptor 2 (Her 2) over expression and/ or amplification. This specific group accounts for approximately $15-20 \%$ of all breast cancer types [4]. TNBC also known to typically express epidermal growth factor receptor 1 (EGFR) and basal cytokeratins (particularly cytokeratin 5, 14 and 17) [30]. These tumours have been characterized by several aggressive clinical pathological features including onset at a younger age, higher mean tumour size, higher grade tumours, and, in some cases, a higher rate of node positivity. Lehmann et al. [4] Epidemiology studies shows thatTNBC occurs more frequently in younger patients ( $<50$ years old) [21].

Triple negative tumours have varied morphological and basal cell features and are generally classified in different groups based on their features; [1] some members of this group, particularly adenoid cystic and secretory carcinomas, have a distinct microscopic appearance which is well recognised by pathologist and is easily distinguishable. However, there are other morphological subgroups of triple negative breast carcinomas which are not well recognized and or characterised. One of these includes triple negative tumours with extensive 'comedo' necrosis.

In contrast to apoptosis, comedo necrosis has been traditionally thought to be a form of an accidental, forced, pathological type of cell death triggered by harsh, external, physical or chemical stimuli. Necrosis can be classified as the final result 
of a bioenergetics catastrophy resulting from ATP depletion to a level incompatible with cell survival and was thought to be initiated mainly by cellular 'accidents' such as toxic insults or physical damage. Morphological appearance of comedo necrosis can be seen by vacuolation of the cytoplasm, breakdown of the plasma membrane and an induction of inflammation around the dying cell attributable to the release of cellular contents and proinflammatory molecules. Cells that die by necrosis frequently exhibit changes in nuclear morphology but not the organized chromatin condensation and fragmentation of DNA. Comedo Necrosis pattern type of necrosis occurs within a gland in which there is central luminal inflammation with devitalized cells, usually occurring in the breast in situ (intraductal) carcinoma.

Whilst the majority of TNBC are ductal in origin; [1,3], several other aggressive phenotypes appear to be over represented, including meta-plastic, and atypical or typical medullary. Although mitosis and necrosis have been recorded as histological feature of TNBC; there is no evidence of a full study conducted on comedo necrosis, which might influence it behaviour pattern in respect of classification and prognostic outlook this study will be the first to undertake this.

There has been a growing interest in recent years to understand the molecular basis of TNBC even though they represent less than $20 \%$ of all breast cancers. These tumours constitute an important clinical challenge, as they do not respond to endocrine treatment and other targeted therapies and they lack the targets for therapies namely ER and HER2 over expression [29]. As a group they harbour an aggressive clinical phenotype with early development of visceral metastases and a poor long-term prognosis. While chemotherapy remains, the conventional treatment used in triplenegative disease, research continues to further identify potential new targets based on phenotypical and molecular characteristics of these tumours.

In this respect, the presence of a higher expression of different biomarkers including epidermal growth factor receptor, vascular endothelial growth factor receptor, fibroblast growth factor receptor and Akt activation has led to a proliferation of clinical trials assessing the role of inhibitors to these pathways in triplenegative tumours [14]. There are limited research undertaken on other biomarkers, so this study attempts to bridge this gap. We evaluated the expression of five biomarkers: Maspin, which is a unique member of the serine protease inhibitor superfamily and it has been shown to have tumour suppressive activity attributable to the inhibition of breast cancer cell motility, invasion and metastasis [20]. Claudin 1, Claudin 3 and Claudin4, which are transmembrane proteins and important components of cell membrane tight junctions (TJs). Claudin 3 and Claudin 4 are expressed in tight junctions and their possible function is to represent one mode of cell-to -cell adhesion in epithelial or endothelial cell sheets, forming continuous seals around cells and serving as a physical barrier to prevent solutes and water from passing freely through the paracellular space. Claudin 1 has found to have an anti- apoptotic effect in tamoxifen-treated human breast cancer MCF-7 cells [5]. along with Cytokeratin 5, and CD10.

The study was aimed to evaluate whether triple negative carcinomas with comedo necrosis subgroup has different clinical pathological and prognostic characteristics from other subgroups of triple negative tumours without comedo necrosis.

\section{Materials and methods \\ Subjects}

A total of 65 archival invasive ductal carcinoma cases from 1996 to 2012 were selected from Charing Cross Hospital surgical database, which immunohistochemistry profile of initial core biopsy, negatively expressed human epidermal growth receptor 2 (Her 2), oestrogen (ER), and progesterone (PgR). Case profiles were female patients, ages 26 to 94 years with mean age of 57.6 years.

\section{Histological assessment}

Archival haematoxylin and eosin stained slides were reviewed from all cases and classified according to their microscopic appearances and placed into two (2) main subgroups; tumours with comedo necrosis and tumours without comedo necrosis. Further to this, case datas were accessed according to age, and lymph node status and reoccurrence status.

\section{Immunohistochemistry}

Ethical approval was granted by Imperial College Healthcare Trust Tissue Bank on 02/07/2014; Project number R1405. From these 7 serial sections of $4 \mu \mathrm{m}$ thick were taken from each archival formalin fixed paraffin embedded tissue tumour blocks using Rotatory Microtome H325 (Leica Biosystems). Once cut the sections were placed in water bath at $45^{\circ} \mathrm{C}$, placed on superfrost plus $\mathrm{IHC}$ microscopic slides and dried in $37^{\circ} \mathrm{C}$ oven. One slide was taken for haematoxylin and eosin staining and the remaining six (6) used for immunohistochemistry studies using the following antibodies. Rabbit anti-Claudin $1 \mathrm{pAb}$ (ab15098) $\left(\right.$ Abcam $^{\mathrm{TM}}$ ), Rabbit anti-Claudin 3 pAb (34-1700) (Life Technologies ${ }^{T M}$ ), mouse anti-Claudin 4 mAb (32-9400) (Life Technologies ${ }^{\mathrm{TM}}$ ) rabbit polyclonal anti-Cytokeratin 5 (ab53121) and anti Maspin (ab66513), and mouse monoclonal CD 10 (MA5-13705) (Thermofisher).

Slides were heated at $60^{\circ} \mathrm{C}$ for 30 minutes, promoting tissue adhesion, before being deparaffinized in two changes of xylene for 5 minutes each and hydrated in 3 changes of $100 \%$ ethanol for 5 minutes each, and running tap water for 5-10 minutes. Heat-mediated antigen retrieval was achieved via steam-heating the tissues in hot citrate buffer $(10 \mathrm{mM}$ sodium citrate, $0.05 \%, \mathrm{pH} 6.0$ ) in a steam heater for 30 minutes. Slides were then allowed to cool down in running water.

Antibodies were prepared with Bond Primary Antibody Diluent (AR9352) (Leica Biosystems ${ }^{\mathrm{TM}}$ ). IHC was performed using a Bond Polymer Refine Detection Kit (DS9800) (Leica Biosystems ${ }^{T M}$ ) of which the constituents are as follows: $4 \%$ hydrogen peroxide block $(30 \mathrm{mls})$, post primary rabbit anti 
mouse lgG $(<10 \mu \mathrm{g} / \mathrm{ml})$ in $10 \%$ bovine serum in tris-buffered saline $(30 \mathrm{mls})$, polymer anti-rabbit poly-HRP-lgG in $10 \%$ bovine serum $(30 \mathrm{mls}), 66 \mathrm{mM} 3,3^{\prime}$-Diaminobenzidine tetrahydrochloride hydrate (DAB) chromogen $(62.4 \mathrm{mls})$ and haematoxylin counterstain $(30 \mathrm{mls})$. Primary antibodies were incubated unto the respective slides for 1 hour, then washed with PBS and incubated with post primary antibody for 20 minutes, followed by polymer for 30 minutes. Visualisation of the Antibody/antigen reaction was achieved via the Bond DAB chromogenic detection kit and the slides were finally counterstained with haematoxylin (Leica Biosystems $\mathrm{s}^{\mathrm{TM}}$ ). Sections were dehydrated using ascending grades of alcohol, cleared in xylene and cover slipped then analysed using a light microscope. For validating sample staining both positive and negative controls were utilised.

\section{Semi quantitative assessment}

The distribution and immunoreactivity of the staining was assessed using a bright-field microscope (Nikon Eclipse 50i) and semi quantitative classification was used to determine the expression status of CK5, CD10, Maspin, Claudin1, Claudin3 and Claudin 4. The whole section was scanned to determine the presence of each marker. The distribution and grading:For CK5 and CD10 cases graded as positive were cases that stained $10 \%$ or more of the tumour cells with the marker and negative staining were cases with less than $10 \%$ had the stained marker. For Maspin, Claudin 1, Claudin3, Claudin 4 marker, cases that showed no staining were graded as negative, cases with weak staining given $+(1+)$; moderate staining given $++(2+)$; and strong staining noted as $+++(3+)$. Distribution of positivity scores of all staining were recorded the percentage calculated. The students unpaired $t$ test was used to analyse the difference between both subgroups. (Supplementary Material of Clinical details and immunostain data are shown in Table 6-9)

\section{Statistical analysis}

Statistical analysis was performed using Chi-Square test, to evaluate correlations between the different variables. A Pearson correlation coefficient was calculated by both clinical characteristics and $\mathrm{IHC}$ scoring for each subgroup to assess a comparative analysis. The variable with prognostic potential in the univariable analyses $(p \leq 0.05)$ and the variables that correlated significantly with one of the parameters were included in the multivariable analysis. A $p$-value $p \leq 0.05$ was considered to indicate statistical significance, a $p \leq 0.01, p \leq 0.001$ and the significance were considered as high and very high respectively.

\section{Results \\ Study Group}

A total of 65 invasive carcinomas with known oestrogen (ER), progesterone (PgR) and human epidermal growth factor (HER2) negative receptors were included. Sixty-two (62) were primary invasive breast cancer cases whilst three (3) were from reoccurrence triple negative cancers.

\section{Histopathological assessment}

From the cases studied, there were various histological features present within these invasive carcinomas, these ranged from adenocystic, secretory, anaplastic, matrix producing metaplastic, (Figure 1) invasive papillary, tumours with comedo necrosis and unclassified (as these showed no striking features or appearance that make them readily distinguishable morphologically) (Supplementary data tables 8 and 9 ).

\section{Demographics}

Results of age assessment revealed; age ranges 26 years to 94 years, mean age \pm SD was 57.6 years. Establishing significance of age ranges for both comedo necrosis type group and non comedo type groups: $<50$ years and $>50$ years. Statistically there was no significance (Table 1).

\section{Immunohistochemistry Findings}

The immuno profile expressions analyses were as follows: Tumours with comedo necrosis CD10 -39.13\%; CK5 -78.26\%; Maspin $-43.47 \%$; Claudin 1 -34.78\%; Claudin $-43.47 \%$ and Claudin4 -78.26\%. Non Comedo type tumours CD10-28.57\%; CK5 -65.11\%; Maspin -52.38\%; Claudin1 -59.52\%; Claudin3 $-50 \%$ and Claudin $4-85.71 \%$ (Figure 2).

From these four (4) markers: Maspin, Claudin1, Claudin3, Claudin4 we analysed, firstly their expression for positivity $(+)$ and negativity (-). Positivity was noted as any amount of staining expressed, whether it ranges from weakly positive to strong staining.

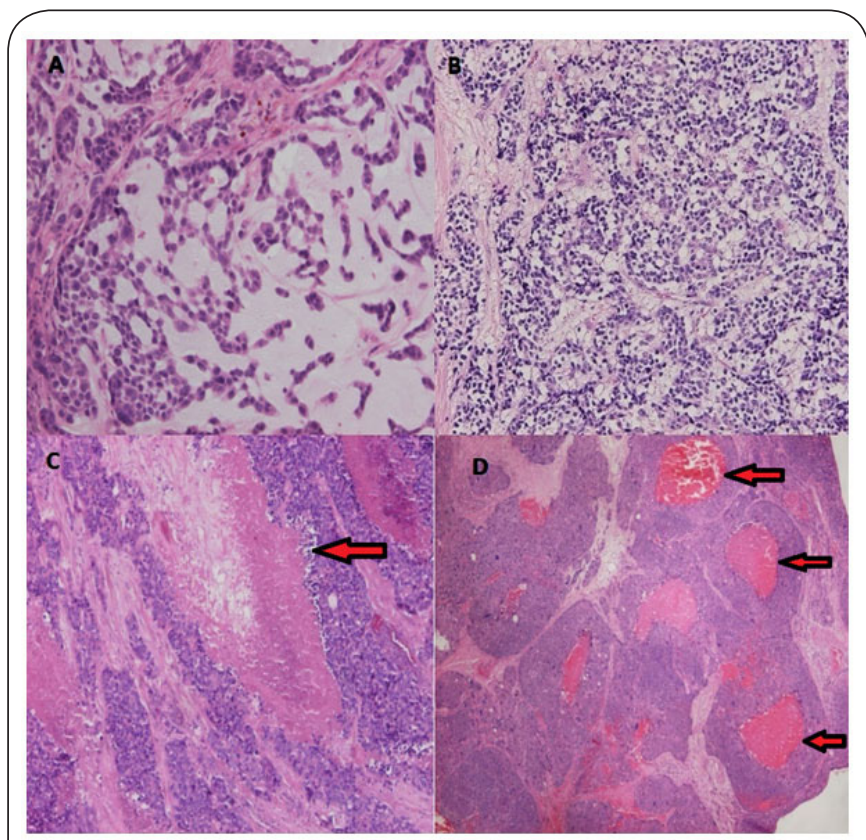

Figure 1. Photomicrographs (A-D) haematoxylin and eosin staining showing histological features of various invasive triple negative carcinomas: (A) matrix producing metaplastic carcinoma; (B) anaplastic carcinoma; (C\&D) arrows indicating tumours with comedo necrosis. 


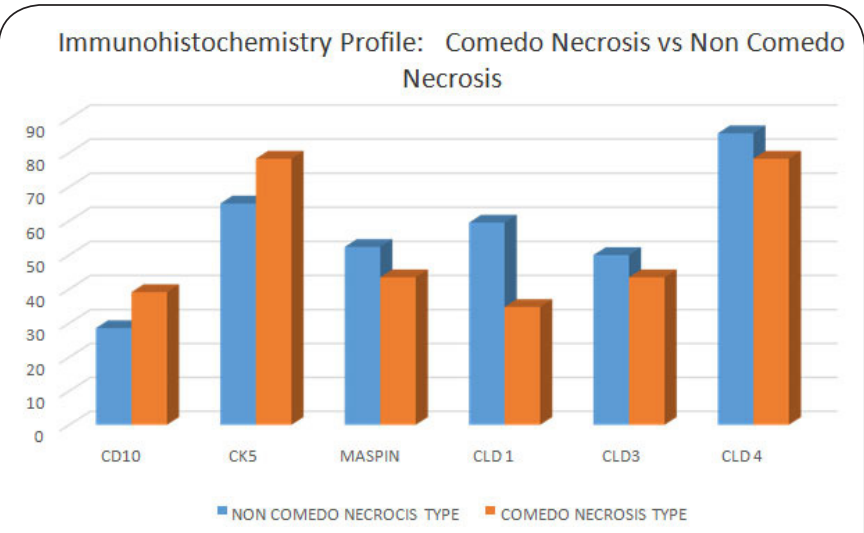

Figure 2. Immunohistochemistry profile ratio of CK10,CK5, Maspin,Claudin 1,3 and 4 in Comedo Necrosis verses Non Comedo Necrosis.

Table 1. Age range Comedo Necrosis type vs Non Comedo Type.

\begin{tabular}{|c|c|c|c|}
\hline & Total & $\begin{array}{l}\text { Comedo Necrosis } \\
\text { Type }\end{array}$ & $\begin{array}{l}\text { Non Comedo } \\
\text { Type }\end{array}$ \\
\hline Number of Cases & 65 & 23 & 42 \\
\hline Age Range & & $26-85$ & $28-76$ \\
\hline$<50$ years & & $7(30.43 \%)$ & $11(26.19 \%)$ \\
\hline \multirow[t]{2}{*}{$>50$ years } & & $16(69.57 \%)$ & $31(73.81 \%)$ \\
\hline & $\begin{array}{l}\text { T-valu } \\
P \text {-Valu }\end{array}$ & $\begin{array}{l}e \text { is } 1.083676 ; \\
\text { e is } 0.2914\end{array}$ & \\
\hline Mean \pm 0.36 & & 57.74 & 57.38 \\
\hline SD & & 17.07 & 14.84 \\
\hline SEM & & 3.56 & 2.29 \\
\hline \multirow[t]{2}{*}{$\mathrm{N}$} & & 23 & 42 \\
\hline & $\begin{array}{l}P=0.9 \\
\text { differe }\end{array}$ & $\begin{array}{l}\text { 3; Standard error of } \\
n c e=4.061\end{array}$ & \\
\hline
\end{tabular}

In comparison of study groups, it proved significantly that tumours with Comedo Necrosis Group yield a high negativity staining for Claudin 1 (65.22\%) when compared to NonComedo Type Group (40.48\%).

In Table 2, Maspin and Claudin3 were marginally equally distributed amongst both groups with Comedo Necrosis type tumours expressing $43.47 \%$ for both Maspin and Claudin 3 marker versus the Non Comedo type that expresses 52.38\% and $50 \%$ positivity respectively.

Claudin 4 had high expression in both subgroups with comedo necrosis tumour group expressed in $78.26 \%$ and non comedo necrosis type $85.71 \%$.

The $T$ test was used to statistically analyse the result to see the significance and the $p$-value $p \leq 0.05$ was considered to indicate statistical significance.

Secondly there were further analysis of the markers into two groups; low groups of staining and high groups of staining. This was achieved by grouping negative or weak expression $(-/+)$ known a 'low expression' and the other group moderate
Table 2. Maspin and Claudin 1, 3, 4 respectively positive immunostain percentiles.

\begin{tabular}{lllll}
\hline & $\begin{array}{l}\text { COMEDO- } \\
\text { TYPE }\end{array}$ & $\begin{array}{l}\text { Non COMEDO- } \\
\text { TYPE }\end{array}$ & \\
\cline { 2 - 4 } & $(10) 43.48 \%$ & $(22) 52.38 \%$ & $\begin{array}{l}\text { T-value is } 0.67831 . \\
\text {-Value is } 0.25003 . \\
\text { (not significant) }\end{array}$ \\
\hline Claudin 1 & $8(34.78 \%)$ & $25(59.52 \%)$ & $\begin{array}{l}\text { T-value is } 1.933128 . \\
P \text {-Value is } 0.028859 . \\
\text { (significant) }\end{array}$ \\
\hline Claudin 3 & $10(43.48 \%)$ & $50 \%$ & $\begin{array}{l}\text { T-value is } 0.500769 . \\
P \text {-Value is } 0.309113 . \\
\text { (not significant) }\end{array}$ \\
\hline Claudin 4 & $18(78.26 \%)$ & $36(85.71 \%)$ & $\begin{array}{l}T \text {-value is } 0.513113 . \\
P \text {-Value is } 0.304848 . \\
\text { (not significant) }\end{array}$ \\
\hline
\end{tabular}

and strong expression (++/+++) known as 'high expression'. Both expression groups were compared in respects of their subgroup (Table 3).

And finally, we went further by making three (3) groups; grouping negative $(-)$, weak and moderate expression $(-/+/++)$ with strong expression $(+++)$ and see its expression pattern in tumours with comedo necrosis group and tumours without comedo necrosis group. The $t$ test was applied to deduce statistical significance.

The hypothesis for this analysis was to evaluate if there was a pattern characteristically attributed to both subgroups of triple negative carcinomas.

From the data retrieved there was no statistical significance between immuno markers in both subgroups when compared low expression, neither was any statistical significance

Table 3. Group comparison of Immunostain Maspin and Claudin 1, 3, 4 graded $(-/+)$ and $(-/+/++)$ versus graded $(++/+++)$ and $(+++)$ in percentage.

\begin{tabular}{|c|c|c|}
\hline & COMEDO-TYPE & Non- COMEDO-TYPE \\
\hline Maspin -/+ & $21(91.3 \%)$ & $37(88.1 \%)$ \\
\hline Maspin $++/+++$ & $2(8.7 \%)$ & $5(11.9 \%)$ \\
\hline Maspin $-/+/++$ & $100.00 \%$ & $100.00 \%$ \\
\hline Maspin +++ & $0.00 \%$ & $0.00 \%$ \\
\hline Claudin $1-/+$ & $20(86.96 \%)$ & $31(73.81 \%)$ \\
\hline Claudin $1++/+++$ & $3(13.04 \%)$ & $11(26.19 \%)$ \\
\hline Claudin $1-/+/++$ & $20(86.96 \%)$ & $38(90.48 \%)$ \\
\hline Claudin $1+++$ & $3(13.04 \%)$ & $4(9.52 \%)$ \\
\hline Claudin $3-/+$ & $21(91.3 \%)$ & $35(83.33 \%)$ \\
\hline Claudin $3++/+++$ & $2(8.7 \%)$ & $7(16.66 \%)$ \\
\hline Claudin $3-/+/++$ & $22(95.65 \%)$ & $40(95.23 \%)$ \\
\hline Claudin $3+++$ & $1(4.35 \%)$ & $2(4.76 \%$ \\
\hline Claudin4 -/+ & $10(43.48 \%)$ & $18(42.86 \%)$ \\
\hline Claudin $4++/+++$ & $13(56.52 \%)$ & $24(57.14 \%)$ \\
\hline Claudin $4-/+/++$ & $20(86.96 \%)$ & $38(90.48 \%$ \\
\hline Claudin $4+++$ & $3(13.04 \%)$ & $4(9.52 \%)$ \\
\hline
\end{tabular}


observed within high expression of these immunomarkers. Photomicrographs of immunohistochemistry expression yield during the staining (Figure 3). Positive tumour cells can be seen with areas of brown to dark brown pigmentation, this reaction occurs from the oxidation of the DAB substrate.

\section{Clinicopathological assessment}

To determine the behavioural pattern within these two groups the clinical pathological statuses were analysed. These include grade of invasive tumour, tumour size, lymph node metastases and lymphovascular invasion. All cases study had invasive ductal carcinoma grade 2 and 3 . Tumours with Comedo Necrosis type group were all grade 3 compared to tumours without Comedo Necrosis (Non Comedo Type) which was grade 2 and 3 . Statistical significance between the two groups are tabulated in Tables $\mathbf{4}$ and $\mathbf{5}$.

The sizes of tumour were compared. Tumours with Comedo Necrosis Group were $8 \mathrm{~mm}$ to $200 \mathrm{~mm}$ in comparison to tumours in the Non-Comedo Necrosis group that was $7 \mathrm{~mm}$ to $100 \mathrm{~mm}$. This was observed to be significant.

Significant findings were observed in the comparison of lymph node metastases and lymphovasuclar invasion statues.

\section{Follow-Up Data}

Follow up data analysed; from initial operation date to all appointments thereafter. Limitations within the study retrieved only data of 56 cases were analysed due to the availability of health records and unreturned records transfers to other Patient Care Trust, also three (3) follow up data were excluded

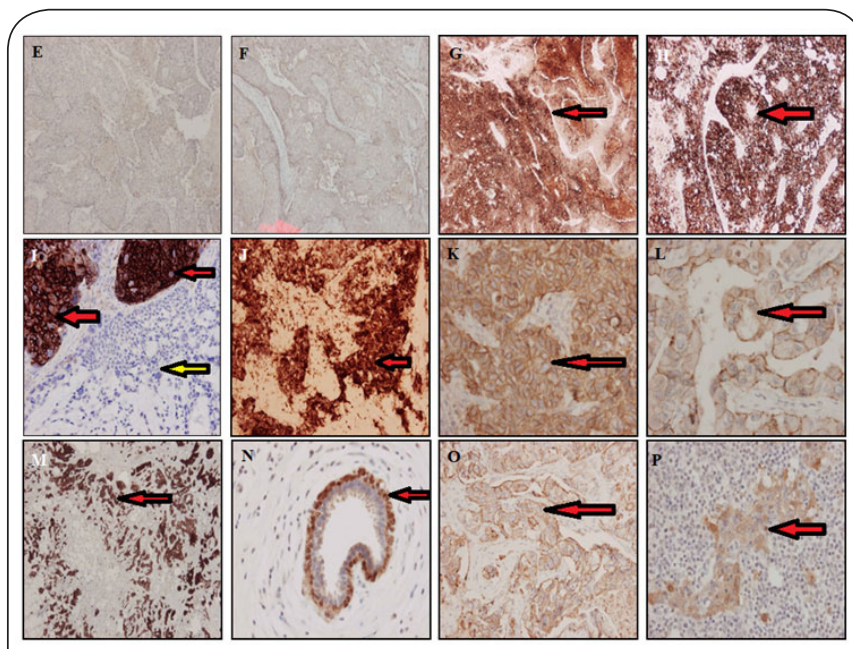

Figure 3. Photomicrographs (E-F) showing: immunostain profile of comedo necrosis tumours. Positivity of stainingis scored by the intensity of dark brownDAB (3,3'-Diaminobenzidine)deposits (E): Claudin-1 negative; $(\mathbf{F})$ : Claudin-3 negative; (G): CD10 positive; $(\mathbf{H})$ : CK5 positive; (I): CD10 positive incomedo areas (red arrow) and negative in metaplastic areas (yellow arrow) ; (J): CD10 positive; (K): Claudin 4 positive $3+$; (L): Claudin 3 positive $2+;(\mathbf{M})$ : Claudin $4+$ /- positive; (N): Maspin positive; $(\mathbf{O})$ : Claudin 3 positive $2+;(\mathbf{P})$ : Maspin positive $2+$.
Table 4. Invasive ductal carcinoma grading comparison for comedo necrosis group verses non comedo type group.

\begin{tabular}{llll}
\hline & IDC-2 & IDC-3 & $\begin{array}{l}\text { Marginal } \\
\text { Row Totals }\end{array}$ \\
\hline COMEDO TYPE & 0 & $\begin{array}{l}23(18.4) \\
{[1.15]}\end{array}$ & 23 \\
\hline NON COMEDO TYPE & $13(8.4)$ & $29(33.6)$ & 42 \\
& {$[2.52]$} & {$[0.63]$} & \\
\hline $\begin{array}{l}\text { Marginal Column } \\
\text { Totals }\end{array}$ & 13 & 52 & $\begin{array}{l}65 \\
\text { (Grand Total) }\end{array}$ \\
\hline
\end{tabular}

The Chi-square statistic is 8.8988 . The $\mathrm{P}$ value is 0.002854 .

This result is significant

Table 5. Clinicopathological Status of Tumours.

\begin{tabular}{|c|c|c|}
\hline \multirow[t]{2}{*}{ Total Number of Cases 65} & $\begin{array}{l}\text { Comedo Necrosis } \\
\text { Group }\end{array}$ & $\begin{array}{l}\text { NON-Comedo } \\
\text { Necrosis Group }\end{array}$ \\
\hline & 23 & 42 \\
\hline \multicolumn{3}{|l|}{ Age } \\
\hline Mean & 56.7 & 56.6 \\
\hline Range & $26-85$ & $28-76$ \\
\hline $\begin{array}{l}\text { Grade } \\
1 \\
\text { Grade } \\
11\end{array}$ & -- & $13(30.95 \%)$ \\
\hline Grade 111 & $23(100 \%)$ & $29(69.05 \%)$ \\
\hline $\begin{array}{l}\text { Tumour Size } \\
\text { Mean (mm) }\end{array}$ & 45.89 & 29.56 \\
\hline Range (mm) & $8-200$ & $7-100$ \\
\hline $\begin{array}{l}\text { Lymph Node } \\
\text { Metastases }\end{array}$ & $3(13.04 \%)$ & $22(52.38 \%)$ \\
\hline $\begin{array}{l}\text { Lymphovascular } \\
\text { Invasion }\end{array}$ & $4(17.39 \%)$ & $23(54.76 \%)$ \\
\hline
\end{tabular}

as patient history shows these were recurrent tumours and this study was designed to analyse primary tumours only.

From the data available, the follow up data ranged from 2 months -124 months giving a median follow up data time to be 37.96 months.

Data for tumours with Comedo Necrosis Group: From 23 cases studied only 21 case data was found. These range from 2 months post operatively to 124 months. From these reoccurrence metastases was seen in only 3 cases. (14.29\%).

Data for Non Comedo Type tumours Group: (Table 5) From the 42 cases studied only data for 32 was found. Three (3) of which was omitted as they were already recurrent tumours. Post-operative data ranges from 4 months to 82 months. The reoccurrence metastases were recorded in 8 cases which gives (27.59\%). These data were very significant findings.

\section{Discussion}

The pathological characteristics in this study confirmed triple negative carcinomas are morphologically aggressive phenotype with most cases being grade 2 and 3 infiltrative ductal carcinomas that measured up to $200 \mathrm{~mm}$ in size. 
From the results based on the lymph node statuses, lymphovascular invasion and follow up metastases it showed tumours with comedo necrosis are less aggressive in its behavioural pattern in comparison to tumours without comedo necrosis.

In analysing the significant in tumour size within both subgroups some tumours grouped in the non comedo type group were cases that had adjuvant therapy. This pre-management would have been administered before primary excision to kill any cancer cells that may have spread and may cause tumour size to shrink and sometimes cannot be detected by imaging or histology; this may be an attributing factor hence the statistical significance within this parameter needs to be investigated further.

The mean and median age of women among the study cohort harbouring triple-negative breast cancer was 57.9 years, and the incidence of women who were 50 years or less among this cohort was not significantly different, both comedo necrosis and non comedo necrosis type group did not show any significance that there was a necessarily age skewed pattern. Researches suggesting that triple negative tumour occurred in predominantly younger women below age 50 was not proven.

In analysing the immunohistochemical assessment of the tumours, DAB (3,3'-Diaminobenzidine) was used as a chromogen; $D A B$ is oxidized by hydrogen peroxide in a reaction which is often catalysed by horseradish peroxidase (HRP). The oxidized DAB forms a brown precipitate, at the location of the HRP, which can be visualized using light microscopy. The intensity of the precipitate denotes the positivity of immune markers and can be classified accordingly into expression analysis.

In investigating tumour grading for both subgroups, although all tumours with comedo necrosis was of IDC grade 3, their lymph node metastases and lympho-vascular invasion were significantly less when compared to tumours without comedo necrosis.

\section{Conclusion}

As triple-negative breast cancers are a heterogeneous group of breast cancers that are generally thought to be aggressive with poor prognosis and have limited treatment strategies compared with tumours expressing hormone receptor [4]. The management of breast cancer relies on traditional prognostic factors including nodal status, tumour histologic grade, and primary tumour size. It is very important to correlate histological features and phenotypical expression when assessing their behaviour as their behaviour pattern is different and knowing this should be managed differently, if this is assessed it will overall give a better prognosis and more effective patient management.

The claudins are a group of small transmembrane proteins located in the tight junctions between epithelial cells which maintain cellular polarity, mediate permeability and are involved in signalling between the cells and their environment.
Most tissues express multiple claudins which are specific for a given tissue or cell. Altered expression of Claudin 1, 3, 4 and 7 has been linked to the development of a variety of cancers especially breast cancer and are thought to be implicated in the metastasis. The alteration can be in the form of over-expression or down regulation depending on the type of cancer [35].

Our observation was both subgroups of tumours expressed high levels of Claudin $4 ; 80.4 \%$ in tumours with comedo necrosis and $84.6 \%$ in tumours without.

Claudin 3 was seen in approximately evenly distributed in each group. However significantly for this project we found that Claudin 1 negativity was higher in tumours with Comedo Necrosis when compared with Non Comedo Type tumours in which Claudin 1 was mostly positively expressed.

From our results we can conclude that tumours with comedo necrosis are more likely to be Claudin 1 negative and have Claudin 1 low expression. These findings show that tumours with comedo necrosis is a positive sign for patient management, Claudin 1 negativity in these tumours could be a putative tumour suppressor andthis down regulation of Claudin1 yields a better prognosis. Hence tumours with comedo necrosis proved to give better prognosis, when managed with conventional therapies.

We can successfully conclude that tumours with comedo necrosis indeed attribute different behaviours than tumours without comedo necrosis and it's in fact a good overall sign for triple negative tumours to have this feature, they are less aggressive. Knowledge of these findings is very beneficial when assessing its management, as it give a very good prognosis for the patient care.

\section{Additional files}

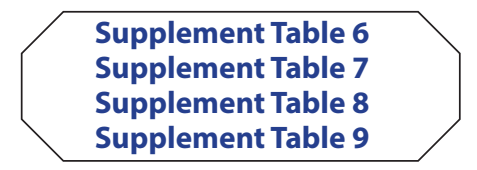

Competing interests

The authors declare that they have no competing interests.

Authors' contributions

\begin{tabular}{|l|c|c|}
\hline Authors' contributions & TM & SS \\
\hline Research concept and design & -- & $\checkmark$ \\
\hline Collection and/or assembly of data & $\checkmark$ & -- \\
\hline Data analysis and interpretation & $\checkmark$ & -- \\
\hline Writing the article & $\checkmark$ & $\checkmark$ \\
\hline Critical revision of the article & $\checkmark$ & $\checkmark$ \\
\hline Final approval of article & $\checkmark$ & $\checkmark$ \\
\hline Statistical analysis & $\checkmark$ & $\checkmark$ \\
\hline
\end{tabular}

\section{Publication history}

Editor: Giuseppe Musumeci, University of Catania, Italy.

Received: 23-Aug-2019 Final Revised: 28-Oct-2019

Accepted: 01-Nov-2019 Published: 17-Nov-2019 


\section{References}

1. Kreike B, van Kouwenhove $M$, Horlings $H$, Weigelt B, Peterse $H$, Bartelink $\mathrm{H}$ and van de Vijver MJ. Gene expression profiling and histopathological characterization of triple-negative/basal-like breast carcinomas. Breast Cancer Res. 2007; 9:R65. | Article | PubMed Abstract | PubMed FullText

2. Kreike B, Halfwerk $H$, Kristel $P$, Glas A, Peterse $H$, Bartelink $H$ and van de Vijver MJ. Gene expression profiles of primary breast carcinomas from patients at high risk for local recurrence after breast-conserving therapy. Clin Cancer Res. 2006; 12:5705-12. | Article I PubMed

3. Turner N, Lambros MB and Horlings HM et al. Integrative molecular profiling of triple negative breast cancers identifies amplicon drivers and potential therapeutic targets. Oncogene. 2010; 29:2013-2023.

4. Lehmann BD, Bauer JA and Chen X et al. Identification of human triplenegative breast cancer subtypes and preclinical models for selection of targeted therapies. J Clin Invest. 2011; 121.

5. Prat A, Parker JS, Karginova O, Fan C, Livasy C, Herschkowitz JI, He X and Perou CM. Phenotypic and molecular characterization of the claudinlow intrinsic subtype of breast cancer. Breast Cancer Res. 2010; 12:R68. | Article | PubMed Abstract | PubMed FullText

6. Morin PJ. Claudin proteins in human cancer: promising new targets for diagnosis and therapy. Cancer Res. 2005; 65:9603-6. | Article I PubMed

7. Lal-Nag M and Morin PJ. The claudins. Genome Biol. 2009; 10:235. | Article | PubMed Abstract | PubMed FullText

8. Singh $A B$, Sharma $A$ and Dhawan P. Claudin family of proteins and cancer: an overview. J Oncol. 2010; 2010:541957. | Article | PubMed Abstract | PubMed FullText

9. Hennessy BT, Gonzalez-Angulo AM, Stemke-Hale K, Gilcrease MZ, Krishnamurthy S, Lee JS, Fridlyand J, Sahin A, Agarwal R, Joy C, Liu W, Stivers D, Baggerly K, Carey M, Lluch A, Monteagudo C, He X, Weigman V, Fan C, Palazzo J, Hortobagyi GN, Nolden LK, Wang NJ, Valero V, Gray JW, Perou CM and Mills GB. Characterization of a naturally occurring breast cancer subset enriched in epithelial-to-mesenchymal transition and stem cell characteristics. Cancer Res. 2009; 69:4116-24. | Article | PubMed Abstract | PubMed FullText

10. Prat A, Parker JS, Karginova O, Fan C, Livasy C, Herschkowitz JI, He X and Perou CM. Phenotypic and molecular characterization of the claudinlow intrinsic subtype of breast cancer. Breast Cancer Res. 2010; 12:R68. | Article | PubMed Abstract | PubMed FullText

11. Lu S, Singh K, Mangray S, Tavares R, Noble L, Resnick MB and Yakirevich E. Claudin expression in high-grade invasive ductal carcinoma of the breast: correlation with the molecular subtype. Mod Pathol. 2013; 26:485-95. | Article | PubMed Abstract | PubMed FullText

12. Turksen K. Claudins and cancer stem cells. Stem Cell Rev Rep. 2011; 7:797-8. | Article | PubMed

13. Dent R, Trudeau M, Pritchard KI, Hanna WM, Kahn HK, Sawka CA, Lickley LA, Rawlinson E, Sun P and Narod SA. Triple-negative breast cancer: clinical features and patterns of recurrence. Clin Cancer Res. 2007; 13:4429-34. I Article I PubMed

14. Lehmann BD and Pietenpol JA. Identification and use of biomarkers in treatment strategies for triple-negative breast cancer subtypes. J Pathol. 2014; 232:142-50. | Article | PubMed Abstract | PubMed FullText

15. Badve S, Dabbs DJ, Schnitt SJ, Baehner FL, Decker T, Eusebi V, Fox SB, Ichihara S, Jacquemier J, Lakhani SR, Palacios J, Rakha EA, Richardson AL, Schmitt FC, Tan PH, Tse GM, Weigelt B, Ellis IO and Reis-Filho JS. Basal-like and triple-negative breast cancers: a critical review with an emphasis on the implications for pathologists and oncologists. Mod Pathol. 2011; 24:157-67. | Article | PubMed

16. Vandana Puri, Manjula Jain, and Shaji Thomas. Stromal Expression of CD10 in Invasive Breast Carcinoma and Its Correlation with ER, PR, HER2-neu, and Ki6. p4061/2011/437957.

17. Huang WB, Zhou XJ, Chen JY, Zhang LH, Meng K, Ma HH and Lu ZF. CD10positive stromal cells in gastric carcinoma: correlation with invasion and metastasis. Jpn J Clin Oncol. 2005; 35:245-50. | Article | PubMed

18. Tokuhara T, Adachi M, Hashida H, Ishida H, Taki T, Higashiyama M, Kodama K, Tachibana S, Sasaki S and Miyake M. Neutral endopeptidase/ CD10 and aminopeptidase N/CD13 gene expression as a prognostic factor in non-small cell lung cancer. Jpn J Thorac Cardiovasc Surg. 2001; 49:489-96. | Article | PubMed

19. Makretsov NA, Hayes M, Carter BA, Dabiri S, Gilks CB and Huntsman
DG. Stromal CD10 expression in invasive breast carcinoma correlates with poor prognosis, estrogen receptor negativity, and high grade. Mod Pathol. 2007; 20:84-9. | Article | PubMed

20. Zou Z, Anisowicz A, Hendrix MJ, Thor A, Neveau M, Sheng S, Rafidi K, Seftor E and Sagar R. Maspin, a serpin with tumour-suppressing activity in human mammary epithelial cells. Science. 1994; 263:526-529.

21. Rakha EA and Ellis IO. Triple-negative/basal-like breast cancer: review. Pathology. 2009; 41:40-7. I Article I PubMed

22. Umekita $Y$, Ohi $Y$, Sagara $Y$ and Yoshida $H$. Expression of maspin predicts poor prognosis in breast-cancer patients. Int J Cancer. 2002; 100:452-5. | Article | PubMed

23. Umekita $\mathrm{Y}$ and Yoshida $\mathrm{H}$. Expression of maspin is up-regulated during the progression of mammary ductal carcinoma. Histopathology. 2003; 42:541-5. | Article | PubMed

24. Rakha EA, Putti TC, Abd El-Rehim DM, Paish C, Green AR, Powe DG, Lee $\mathrm{AH}$, Robertson JF and Ellis IO. Morphological and immunophenotypic analysis of breast carcinomas with basal and myoepithelial differentiation. J Pathol. 2006; 208:495-506. | Article | PubMed

25. Stirzaker C, Zotenko E, Song JZ, Qu W, Nair SS, Locke WJ, Stone A, Armstong NJ, Robinson MD, Dobrovic A, Avery-Kiejda KA, Peters KM, French JD, Stein S, Korbie DJ, Trau M, Forbes JF, Scott RJ, Brown MA, Francis GD and Clark SJ. Methylome sequencing in triple-negative breast cancer reveals distinct methylation clusters with prognostic value. Nat Commun. 2015; 6:5899. | Article | PubMed

26. Elsawaf Z, Sinn HP, Rom J, Bermejo JL, Schneeweiss A and Aulmann S. Biological subtypes of triple-negative breast cancer are associated with distinct morphological changes and clinical behaviour. Breast. 2013; 22:986-92. | Article | PubMed

27. Eiermann W, Bergh J, Cardoso F, Conte P, Crown J, Curtin NJ, Gligorov J, Gusterson B, Joensuu H, Linderholm BK, Martin M, Penault-Llorca F, Pestalozzi BC, Razis E, Sotiriou C, Tjulandin S and Viale G. Triple negative breast cancer: proposals for a pragmatic definition and implications for patient management and trial design. Breast. 2012; 21:20-6. | Article | PubMed

28. Thike AA, Iqbal J, Cheok PY, Chong AP, Tse GM, Tan B, Tan P, Wong NS and Tan $\mathrm{PH}$. Triple negative breast cancer: outcome correlation with immunohistochemical detection of basal markers. Am J Surg Pathol. 2010; 34:956-64. | Article | PubMed

29. Elias AD. Triple-negative breast cancer: a short review. Am J Clin Oncol. 2010; 33:637-45. | Article | PubMed

30. Zhou L, Li K, Luo Y, Tian L, Wang M, Li C and Huang Q. Novel prognostic markers for patients with triple-negative breast cancer. Hum Pathol. 2013; 44:2180-7. | Article | PubMed

31. Jiao Q, Wu A, Shao G, Peng H, Wang M, Ji S, Liu P and Zhang J. The latest progress in research on triple negative breast cancer (TNBC): risk factors, possible therapeutic targets and prognostic markers. J Thorac Dis. 2014; 6:1329-35. | Article | PubMed Abstract | PubMed FullText

32. Bosch A, Eroles P, Zaragoza R, Vina JR and Lluch A. Triple-negative breast cancer: molecular features, pathogenesis, treatment and current lines of research. Cancer Treat Rev. 2010; 36:206-15. | Article | PubMed

33. Ismail-Khan R and Bui MM. A review of triple-negative breast cancer. Cancer Control. 2010; 17:173-6. I Article I PubMed

34. Siegel R, Ma J, Zou Z and Jemal A. Cancer statistics, 2014. CA Cancer J Clin. 2014; 64:9-29. | Article | PubMed

35. Osanai M, Takasawa A, Murata M and Sawada N. Claudins in cancer: bench to bedside. Pflugers Arch. 2017; 469:55-67. | Article | PubMed

\section{Citation:}

McFarlane T and Shousha S. A Clinical Perspective on Triple Negative Invasive Breast Carcinomas with Comedo Necrotic Features. J Histol Histopathol. 2019; 6:7. http://dx.doi.org/10.7243/2055-091X-6-7 